Recepción: 20 / 04 / 2017

Aceptación: 20 / 05 / 2017

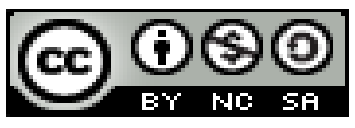

Ciencias de la Salud

Publicación: 15 / 07 / 2017

Artículo Científico

\title{
Estudio correlacional de las técnicas quimiolumiscencia y P.C.R. para el diagnóstico de Hepatitis C
}

Correlacional study of chemiluminescence and P.C.R. for the diagnosis of Hepatitis C

Estudo de correlação de técnicas de quimiluminescência e P.C.R. para diagnosticar a hepatite C

Esthela N. Tinoco-Moreno ${ }^{\mathrm{I}}$ esthela.tinocom@ug.edu.ec

Alex F. Vivas-Lara II alex.vivas1@ug.edu.ec

Jonathan G. Córdova-Ochoa ${ }^{\text {III }}$ jcordovao@gmail.com

Manuel I. Arcos-González IV manuelarcosig@gmail.com

Correspondencia: esthela.tinocom@ug.edu.ec 


\section{Resumen}

La hepatitis $\mathrm{C}$ es una enfermedad infecciosa viral, que puede tener un inicio agudo asintomático pero en la mayoría de los casos tiende a la cronicidad, su estudio y métodos de diagnóstico son de análisis permanente por los gastos que esta representa para los Sistemas de Salud El objetivo de este trabajo es demostrar la correlación entre los resultados positivos encontrados por el método de Quimioluminiscencia contrastando con el método de Reacción en Cadena de Polimerasa. Se seleccionaron 110 pacientes con resultados positivos para quimioluminiscencia filtrados del sistema Datalab de Laboratorio del Hospital Teodoro Maldonado Carbocon diagnóstico de Hepatitis C , y que posteriormente fueron sometidos a amplificación genómica con el método de Reacción en Cadena de Polimerasa, las variables edad, sexo y factores de riesgo se obtuvieron de la Historia Clínica en el sistema informático AS400 . Solamente en 4 (3,6\%) pacientes se pudo detectar carga viral positiva. A la vista de los resultados nos dimos cuenta que la prueba de quimioluminiscencia tiene una gran sensibilidad pero baja especificidad, por lo que no es suficiente para poder realizar un diagnóstico de hepatitis C. Los casos sospechosos de contagio por virus de hepatitis C deben pasar por una prueba confirmatoria como el PCR para encontrar la carga viral y asegurar el diagnóstico ya que, el método de quimioluminiscencia, por sí solo, no da un resultado fidedigno, debido a su alta sensibilidad y baja especificidad.

Palabras clave: Virus; hepatitis C; quimioluminiscencia; infecciosa; asintomático. 


\section{Summary}

Hepatitis $\mathrm{C}$ is an infectious viral disease, which can have an asymptomatic acute onset but in most cases tends to chronicity, its study and methods of diagnosis are of permanent analysis by the expenses that this represents for the Health Systems Objective : The objective of this work is to demonstrate the correlation between the positive results found by the Chemiluminescence method in contrast to the Polymerase Chain Reaction method. Material and methods: We selected 110 patients with positive results for chemiluminescence filtered from the Datalab laboratory system of the Teodoro Maldonado Hospital Carbocon diagnosis of Hepatitis C, which were subsequently subjected to genomic amplification using the Polymerase Chain Reaction method, age variables, Sex and risk factors were obtained from the Clinical History in the AS400 computer system. Results and Discussion: Only positive viral load was detected in $4(3.6 \%)$ patients. In view of the results we realized that the chemiluminescence test has a high sensitivity but low specificity, so it is not enough to make a diagnosis of hepatitis $\mathrm{C}$. Conclusions: suspected cases of hepatitis $\mathrm{C}$ virus infection should Pass a confirmatory test such as PCR to find the viral load and ensure the diagnosis because the chemiluminescence method alone does not give a reliable result due to its high sensitivity and low specificity.

Key words: Virus; hepatitis C; chemiluminescence; infectious; asymptomatic. 


\section{Resumo}

A hepatite $\mathrm{C}$ é uma doença infecciosa viral, o qual pode ter um início agudo assintomática mas na maioria dos casos ele tende a cronicidade, estudo e métodos de diagnóstico são análise permanente para os custos que representa para Sistemas de Saúde Objectivo o objectivo deste trabalho é o de demonstrar a correlação entre os resultados positivos encontrados pelo método de quimioluminescência em contraste com o método de reacção em cadeia da polimerase. Métodos: 110 pacientes foram seleccionados com resultados positivos para a quimioluminescência filtrados sistema Datalab O diagnóstico laboratorial do Hospital Teodoro Maldonado Carbocon de hepatite C, e foram subsequentemente sujeitos a amplificação genómica com o método de reacção em cadeia da polimerase, a idade variáveis, sexo e fatores de risco foram obtidos a partir da história clínica nos .Results AS400 sistema de computador e discussão: Apenas em 4 (3,6\%) pacientes poderia ser detectada carga viral positiva. Em vista dos resultados, percebemos que a prova da quimiluminescência tem uma alta sensibilidade, mas baixa especificidade, por isso não é suficiente para fazer um diagnóstico da hepatite C. Conclusões casos de suspeita de infecção pelo vírus da hepatite C deve submeter-se a um teste de confirmação tal como a carga viral de PCR para localizar e confirmar o diagnóstico, porque o método de quimioluminescência, por si só, não dá um resultado preciso, devido a sua elevada sensibilidade e especificidade baixa.

Palavras-chave: Vírus; Hepatite C; quimioluminescência; infecciosa; assintomáticos. 


\section{Introduccion.}

La infección por el virus de la hepatitis C (VHC) tiene un gran impacto a nivel mundial, infectando a una estimado de 170 millones de personas, considerándose una de las principales causas de hepatitis crónica, enfermedad hepática terminal y hepatocarcinoma. El virus de la hepatitis C (VHC) tiene demostrado poder oncogénico. Su asociación con Carcinoma Hepatocelular (CHC) en pacientes con cirrosis hepática es bien conocida como también con el Linfoma no Hodgkin indolente. Se estima que se generan entre tres y cuatro millones de casos nuevos por año, $8.6 \%$ con virus de hepatitis C (VHC). En España, el VHC constituye en el momento actual el principal factor de riesgo asociado a la aparición de CHC, y aunque los datos son heterogéneos, dado que en muchas ocasiones las metástasis hepáticas son registradas como tumores hepáticos primarios, existen evidencias de que la incidencia de $\mathrm{CHC}$ ha aumentado en los últimos años· En los Estados Unidos, su incidencia se encuentra en aumento de forma muy abrupta, lo cual se ha relacionado por un aumento en la incidencia del VHC.

Las infecciones por virus de hepatitis son generalmente asintomáticas $\mathrm{y}$, en algunos individuos infectados con VIH, que tienen una respuesta inmunitaria disminuida, estas infecciones pueden escapar al control inmunitario y generar enfermedad crónica que algunas veces está oculta, definida como viremia detectable con o sin evidencia serológica de infección y con o sin alteración de las transaminasas. En el Ecuador para el año 2007 se sabe que la Cruz Roja recibió 144.600 donaciones de sangre de manera voluntaria; donde 481 de estas aportaciones se descubrió hepatitis B en un $0,33 \%$ y hepatitis $\mathrm{C}$ un $0,42 \%$.

La terapia antiviral efectiva, definida como respuesta viral sostenida (RVS) mejora el pronóstico global de los infectados. Los esquemas terapéuticos actuales, con antivirales de acción directa, han 
logrado altas tasas de eficacia terapéutica (RVS > 90\% en la mayoría de los grupos) con un adecuado perfil de seguridad.

El objetivo de este estudio fue identificar la correlación entre los resultados positivos de quimioluminiscencia y las pruebas de carga viral que resultaron positivas. Además poder saber el sexo predominante en ambas pruebas, y los rangos de edad con mayor aparición de casos. También se buscó los antecedentes y factores de riesgo que hayan podido ocasionar el contagio.

\section{Materiales y métodos.}

Estudio retrospectivo, observacional, descriptivo, y analítico que se realizó durante el periodo de enero del 2016 a mayo del 2017, donde se evaluó la correlación de los pacientes con sospecha de VHC positivos por quimioluminiscencia y su diagnóstico definitivo por PCR. El estudio se basó en los resultados obtenidos de los pacientes en el sistema DataLab, los informes médicos de evolución y los datos del laboratorio que fueron tomados del sistema AS400 para confirmar si existieron factores de riesgo en los casos confirmados. Se evaluó el grupo etario y sexo con mayor incidencia de resultados positivos por ambos métodos. Además de ello se avaluaron a otro grupo de pacientes que presentaron carga viral positiva, pero sin prueba de quimioluminiscencia previa registrada dentro del Hospital, para poder conseguir la media de la carga viral registrada. Se obtuvieron estadísticas descriptivas de los resultados obtenidos. 


\section{Resultados.}

Grafico 1: Número de casos positivos de quimioluminiscencia de acuerdo al sexo.

\section{Número de casos positivos de quimioluminiscencia de acuerdo al sexo}

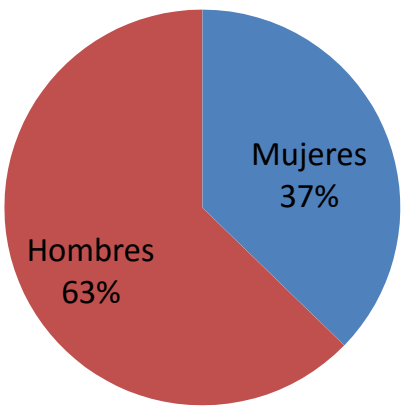

De la muestra de 110 pacientes que en el periodo de estudio presentaron resultado positivo por la técnica de quimioluminiscencia, 41, el 37,2\% eran mujeres y 69, el 62,7\% eran varones.

Grafico 2: Intervalo de Edad de casos con Quimioluminiscencia

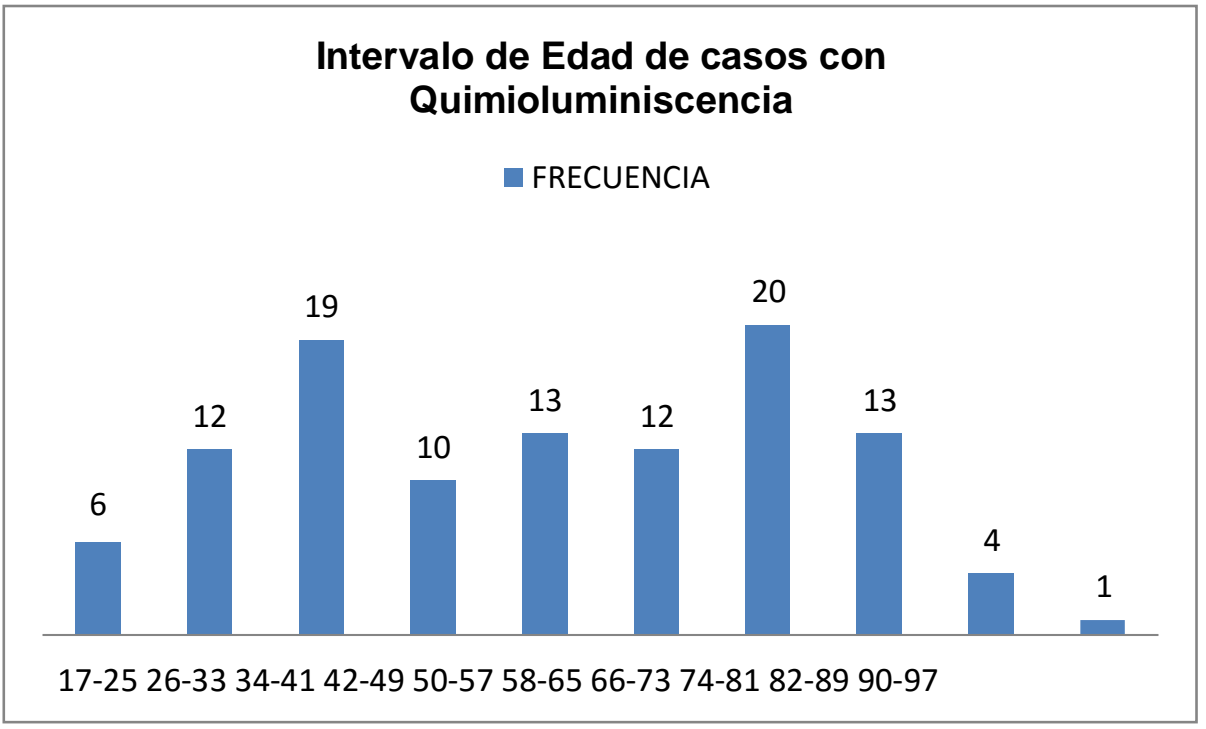


Con relación al intervalo de edad, se encontró que las edades de los pacientes fluctuaron entre 17 y 97 años., Al determinar el rango de edad encontramos una incidencia de 20 casos (18.1\%) en un rango de edad entre 66 y 73 años. Seguida de una incidencia de 19 casos $(17,2 \%$ ?en pacientes entre 34 y 41 años.

Grafico 3: Resultados por medio de técnica de quimioluminiscencia para la Identificación de AntiVHC

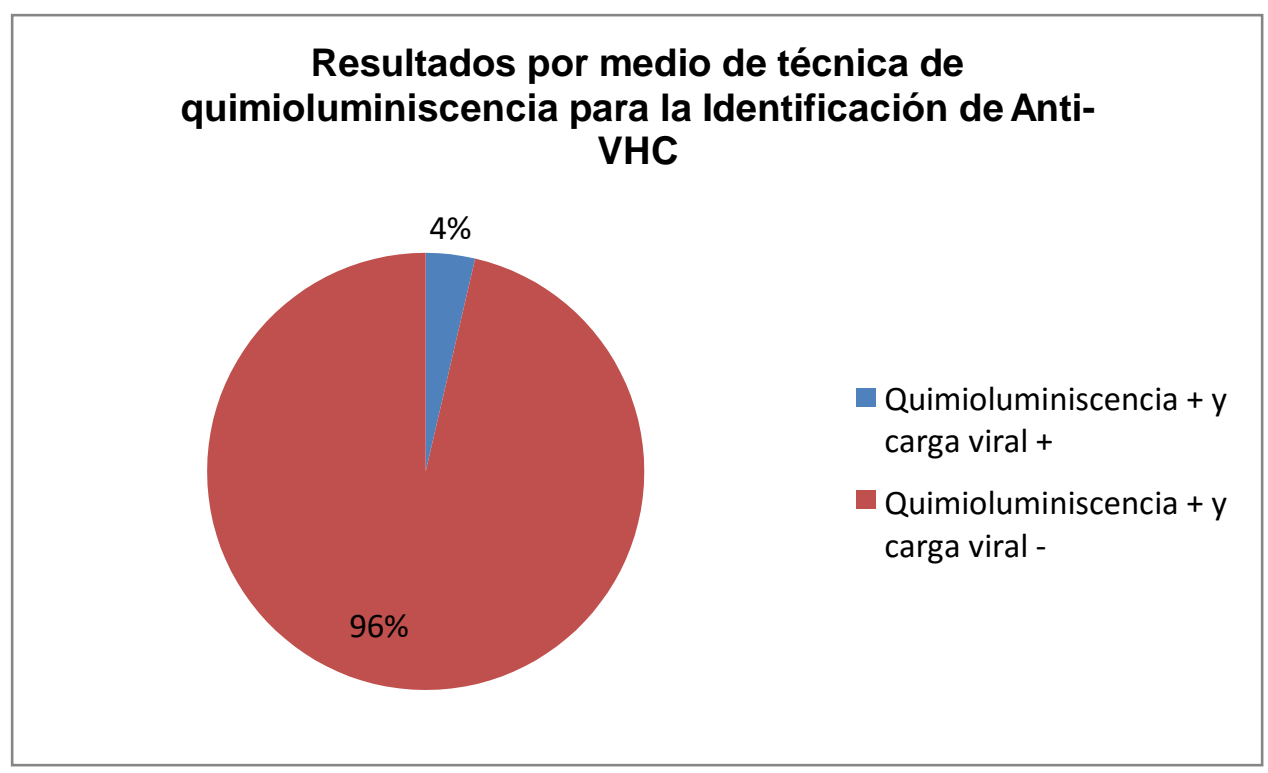

De la muestra de 110 pacientes con resultado positivo por medio de técnica de quimioluminiscencia para la identificación de Anti-VHC, solamente en 4 (3,6\%) pacientes, se detectó ARN viral con carga suficiente para ser considerada positiva. 
Tabla 1: Antecedentes de Pacientes Quimioluminiscencia y carga viral positivos

\begin{tabular}{|c|c|c|}
\hline $\begin{array}{c}\text { Pacientes con Quimioluminiscencia } \\
\text { y carga viral positivos }\end{array}$ & Antecedentes & Factor de Riesgo \\
\hline 1 & $\begin{array}{c}\text { Insuficiencia renal crónica, } \\
\text { diabetes }\end{array}$ & $\begin{array}{c}\text { Hemodiálisis, } \\
\text { transfusión sanguínea }\end{array}$ \\
\hline 2 & $\begin{array}{c}\text { Insuficiencia renal crónica, lupus } \\
\text { eritematoso sistémico } \\
\text { Insuficiencia renal crónica, } \\
\text { diabetes }\end{array}$ & $\begin{array}{c}\text { Hemodiálisis, } \\
\text { transfusión sanguínea }\end{array}$ \\
\hline 3 & $\begin{array}{c}\text { Transfusión sanguínea } \\
\text { Diabetes, hipertensión arterial, } \\
\text { sífilis, virus de la hepatitis B }\end{array}$ & $\begin{array}{c}\text { Conducta sexual y } \\
\text { tatuajes. }\end{array}$ \\
\hline 4 & & \\
\hline
\end{tabular}

Entre los Antecedentes identificados, en los pacientes en quienes se encontró positividad en ambas pruebas, 3 de 4 pacientes presentaban IRC junto con otra comorbilidad como DM, LES, HTA, y en uno de ellos se identificó además positividad para VHB y sífilis, junto con prácticas sexuales de riesgo y tatuajes.

\section{Discusión.}

- El diagnóstico da infección por el VHC se basa en la demostración de la presencia de los anticuerpos anti-VHC e de ARN-VHC y en la presencia de signos biológicos o histológicos de hepatitis crónica. En el caso de una infección por VHC reciente, el aclaramiento viral espontáneo es poco común más allá de los 4 o 6 meses de infección.

- $\quad$ Cuando el examen de detección de anticuerpos anti-VHC determina que presenta la infección, siendo positivo, lo siguiente es ejecutar otra prueba de 'ARN', (ácido ribonucleico), también se le conoce como, RCP “'Reacción en cadena de la polimerasa', el resultado de estas 
pruebas nos confirman si la persona presenta o hay infección crónica, ya en un 15 y $45 \%$ de las personas hay infección por VHC, excluye de manera natural la infección, por una respuesta inmunitaria, lo que significa es que tienen el anticuerpo anti-VHC, pero no el virus.

- $\quad$ En un estudio a pacientes en programa de hemodiálisis con diagnóstico de hepatitis $\mathrm{C}$ se ha descrito mayor incidencia de seroconversión en el sexo masculino, pero no se ha encontrado una explicación para ello, aunque puede influir que el número de pacientes de este sexo en el plan de hemodiálisis sea superior $\mathrm{y}$, de hecho, esto hace que el número de los expuestos a la infección también lo sea.

- $\quad$ En un estudio donde se evaluaron 100 muestras con LIAISON con un índice S/CO anti-VHC entre $\geq 1,00 \mathrm{y} \leq 3,00$, al ser ensayadas con ARCHITECT, solo 29 de ellas resultaron positivas. Los resultados de las 100 muestras ensayadas mediante el reactivo de Abbott, y a continuación con el ensayo de DiaSorin, aparecen solo 40 de ellas presentaron un resultado positivo con el segundo ensayo. Solamente en 8 (4\%) del total de las muestras seleccionadas pudo detectarse ARN viral.

- Los resultados encontrados en nuestro estudio indican que, 110 pacientes pasaron por una sola prueba de quimioluminiscencia, pero sólo 4 (3,6\%) llegaron a presentar carga viral positiva. En este caso se demostró que mediante la prueba de quimioluminiscencia en estos pacientes, los resultados positivos no fueron confiables en una gran mayoría de los casos ya que la falta de especificidad del método nos lleva a realizar una confirmación de los casos con carga viral para VHC, demostrando una reducción drástica del número de casos, a los que realmente son positivos.

- $\quad$ En el caso a la prevalencia por sexo, se vio que hay una gran predilección por el sexo masculino en los casos de quimioluminiscencia con un $62,7 \%$ de hombres pero los resultados confirmatorios por carga viral muestran una prevalencia del $75 \%$ correspondiente al sexo femenino. 
- $\quad$ El rango de edad con más pacientes positivos para quimioluminiscencia en nuestro estudio fue entre 66-73 años (20 casos), seguido de un rango de 34-41 años (19 casos). Esta prevalencia de edades, parece coincidir con el rango de edades de las personas de esta época, ya que tenemos al menos 3 casos positivos que coinciden.

\section{Conclusiones.}

Los casos sospechosos de contagio por virus de hepatitis $\mathrm{C}$ deben pasar por una prueba confirmatoria como el PCR para encontrar la carga viral y asegurar el diagnóstico ya que, el método de quimioluminiscencia, por sí solo, no da un resultado fidedigno, debido a su alta sensibilidad y baja especificidad.

Que los pacientes que reciben hemodiálisis es una población altamente riesgosa de contagiarse con Hepatitis $\mathrm{C}$ porque la prevalencia de esta patología en pacientes que reciben este tipo de terapia es frecuente.

\section{Bibliografía.}

Aguilar-Olivos N, Gutiérrez- Grobe Y, Motola M. Prevalencia del carcinoma Hepatocelular en hígado no cirrótico, Revista de Investigación Médica Sur México, pag. 12015.

Lastra María. Virus de la hepatitis C: variabilidad en las regiones del CORE y NS5A y su impacto en la infección por el genotipo 1b, Tesis doctoral, pag. 62015.

García, L; Boschero, F; del Rio, V; Balbín, E; Espeche, W, carcinoma hepatocelular y linfoma folicular en paciente cirrótico por virus de la hepatitis c, Revista de la Facultad de Ciencias Médicas Tercera Época, pag. $1,2016$.

Fornera Alejandro, Reiga María. Diagnóstico y tratamiento del carcinoma hepatocelular. Actualización del documento de consenso de la AEEH, SEOM, SERAM, SERVEI y SETH, ELSERVIER, pág. 3, 2016.

Tigreros, José Pablo Jiménez, Oncología: Hepatocarcinoma, Revista Médica de Costa Rica y Centroamérica LXXII, pág. 1, 2015.

Segoviano Georgina, Torres Darwin, Tovar Alejandro.Coinfección con virus de hepatitis B o C en pacientes infectados por VIH, Medicina Interna México, pág., 3, 2014. 
Ruiz Alex, Soza Alejandro. Tratamiento de la hepatitis C en cirrosis: beneficios y riesgos, Gastroenterol. latinoam: Patología hepática, pág. 562016.

Gonzales Ruth Noemi, Estudio de hepatitis C en personas nacidas entre 1945, conocida como la época BABY BOOMERS. En el personal de una universidad de Quito, UDLA, Facultad de Ciencias Médicas, pág. $5,2015$.

Méndez Nahum, Ridruejo Ezequiel. Asociación Latinoamericana para el Estudio del Hígado (ALEH) Guías Clínicas para el Manejo del Carcinoma Hepatocelular, ANNALS of hepatology, pág. 58 .2014.

Contreras, Ana María, Anticuerpo a hepatitis C: ¿verdadero o falso positivo? Nuevas estrategias de diagnóstico., RIC Foro Clínico, 2016.

Pereira, Rute Alexandra Soalheira Valido, Hepatitis C: diagnóstico y monitorización laboratorial, Maestría en análisis clínicos, 2015.

Pawlotsky,: Jean-Michel; Miembros de panel: Alessio Aghemo (EASL Junta Directiva), David Back, Geoffrey Dusheiko, Xavier Forns, Massimo Puoti, Christoph Sarrazín, Guías de práctica clínica, EASL: Guías de Práctica Clínica, 2015.

Deyanira La Rosa Hernández. Infección de Hepatitis B y C en pacientes hemodializados. Rev Habanera de Ciencias Médicas. Vol.15 no.6. La Habana nov.-dic. 2016

Cardona, N. E., González, K. D. V., Garzaro, D. J., Loureiro, C. L., Duarte, M. C., García, D. M. Pujol, F. H. Desempeño de estuches comerciales para el diagnóstico serológico de las hepatitis virales B y C en poblaciones yanomami y piaroa del estado Amazonas. Revista de la Sociedad Venezolana de Microbiología, 2010 .

Martínez Fátima, López Fabala. Valoración de sueros con bajo índice S/CO utilizando 2 sistemas de quimioluminiscencia para la detección de anticuerpos frente al virus de la hepatitis C y su correlación con la detección de ARN viral, El Servier: Enfermedades infecciosas y microbiología clínica, 2017, pág. 2.2016.

López María, Pérez Alfredo. Valoración de sueros con bajo índice S/CO utilizando 2 sistemas de quimioluminiscencia para la detección de anticuerpos frente al virus de la hepatitis $\mathrm{C}$ y su correlación con la detección de ARN viral, El Servier: Enfermedades infecciosas y microbiología clínica, pág. 26, 2017.

Galbraith, J. W., Franco, R. A., Donnelly, J. P., Rodgers, J. B., Morgan, J. M., Viles, A. F. Wang. Un recognized chronic hepatitis $\mathrm{C}$ virus infection among baby boomers in the emergency department. Hepatology, 61(3), 776-782. EE.UU. 2015

Grebelya J. Robaeysb G. Recomendaciones para el manejo de la infección por el virus de la hepatitis C entre usuarios de drogas por vía parenteral, ELSEVIER. Pág. 8. 2015. 